\title{
How Does Rapid Automatized Naming (RAN) Correlate with Measures of Reading Fluency in Arabic
}

\author{
Raphiq Ibrahim \\ Edmond J. Safra Brain Research Center \& Department of Learning Disabilities, University of Haifa, Haifa, Israel \\ Email: raphiq@psy.haifa.ac.il
}

Received 31 January 2015; accepted 21 February 2015; published 26 February 2015

Copyright (C) 2015 by author and Scientific Research Publishing Inc.

This work is licensed under the Creative Commons Attribution International License (CC BY).

http://creativecommons.org/licenses/by/4.0/

cC) (7) Open Access

\begin{abstract}
The main goal of this study was to investigate the relationship between naming speed and reading in Arabic language. For this purpose, Arabic-speaking children of third and fifth grades were given a battery of tests including two measures of naming speed and a test of pseudo-word reading and single word reading. Correlations analyses were carried out to explore this relationship. The result of this study revealed a significant relationship between naming speed measures and fluency. This suggests that naming speed ability is a key component in reading acquisition in Arabic and this was discussed with regard to the cross-linguistic research literature as well as the specific features of Arabic language.
\end{abstract}

\section{Keywords}

Naming Speed, Reading, Fluency, Phonology, Arabic

\section{Introduction}

The roles of different aspects of reading vary in their importance and contribution to reading development based on the characteristics of specific language. Phonological awareness has been proven to be a key component in the development of reading ability, and that poor phonological awareness might be the core deficit in reading disability. However, cross linguistic data has pointed to the importance of naming speed in reading development and its contribution to reading, specially, in shallow orthographies. However, the literature on the relationship between naming speed and reading in Arabic is scarce, and what exist focuses on other languages.

Rapid Automatized Naming-RAN

Data have accumulated in the past few decades pointing to the importance of naming speed (NS, also known 
as rapid automatized naming [RAN] or speed of lexical access) in reading development and its contribution to reading disability (e.g., Badian, 1997; Scarborough, 1998a; Wolf \& Bowers, 1999; Wolf, O’rouke, Gidney, Lovett, Cirino, \& Morris, 2002). RAN of visually presented symbols has also come to assume pride of place as a measure of reading fluency. Consistent results indicate that dyslexic subjects perform these tasks at a slower rate than regular readers. This research was begun by Geshwind (1972) who suggested that the ability to name colors may predict a child's reading ability. He also suggested that the cognitive components involved in naming colors constitute a good representation of the cognitive components needed for reading. As in reading, naming requires the attachment of verbal labels to visual stimuli. This hypothesis was developed in a series of studies by Denckla and Rudel (1974, 1976a, 1976b) in which sequential naming tasks were used to examine children's ability to name familiar visual stimuli (e.g., letters, digits, colors and simple objects).

There is little disagreement concerning the behavioral evidence of NS deficits in dyslexic readers, and the independence of this deficit from phonological awareness. This issue is of great importance since adopting one or the other view dictates many aspects of diagnosis and treatment. If current practice places NS problems as part of phonological deficit, then no direct assessment or intervention will be targeted to this cognitive ability. If, on the other hand, phonological and NS processes are seen as two independent sources of breakdown, there are critical implications for diagnosis, sub-typing efforts, and, most importantly, intervention (Wolf \& Bowers, 1999). The question remains, of how independent NS is from phonological ability.

Many investigators subsume NS under phonological processes: For example, "retrieval of phonological codes from a long-term store” (Wagner, Torgesen, Laughon, Simmons, \& Rashotte, 1993: p. 84), or phonological recoding in lexical access (Wagner \& Torgensen, 1987). Only recently have researchers tended to view namingspeed processes as separate, specific sources of disability (e.g., Meyer \& Feloton, 1999). Bowers and Wolf (1993) developed an alternative conceptualization of development reading disabilities to the well known phonological deficit view. This double deficit hypothesis incorporates both phonology and NS processes as two separate sources of reading breakdown. To support their case for separate deficit status, the authors presented five types of evidence about NS: 1) its cognitive requirements; 2) data from diverse populations; 3) cross-linguistic findings; 4) its independence from phonological awareness tasks in predicting various aspects of reading skills; and 5) subtype distinctions that include rate dimensions (Wolf \& Bowers, 1999). According to the double-deficit hypothesis, the combined presence of phonological and NS deficits leads to profound reading impairment. While the two deficits and their combination do not encompass all the possible sources of breakdown in reading failure, this view provides a more comprehensive understanding of the heterogeneity of impaired readers by directing attention to a second, major source of breakdown.

Since then, many researchers have reported independent and significant contributions of NS to reading. Wolf and his colleagues (2002) investigated the independence of phonological and NS deficits in three aspects of reading in severely impaired readers in second and third grade. They found that phonological measures contribute more of the variance to the aspects of reading that involve decoding or word attack skills; and that NS measures contribute more to skills involved in word identification. Subtype classification findings were also supportive of the independence of the two deficits: $19 \%$ of the sample had single phonological deficits, $15 \%$ had single NS deficits, 60\% had double-deficits, and 6\% could not be classified.

Katzir, Wolf, O’Brien, Kennedy, Lovett and Morris (2006) examined the relative contributions of phonological awareness, orthographic pattern recognition, and rapid letter naming to fluent word and connected-text reading in a sample of 123 dyslexic children in second and third grade. In their study, the relationship between rapid letter naming and phonological measures was investigated. Rapid letter naming was significantly correlated with Elision, but the magnitude of the relationship was small $(r=.21, p=.02)$, and there was no significant relationship with blending. When the relative contributions of the different variables were evaluated by a hierarchical regression model, rapid letter naming and Elision added independent variance to word identification for accuracy and latency (Katzir, Wolf, O’Brien, Kennedy, Lovett, \& Morris, 2006: p. 70).

Another source of support for the independence of NS and phonological awareness comes from research conducted in languages other than English, including German (Wimmer, 1993; Wimmer et al., 2000), Spanish (Escribano \& Katzir, 2008; Jimenez, Hernandez, Rodriguez, Guzman, Diaz, \& Ortiz, 2008) and Dutch (van den Bos, 1998; Yap \& van der Leij, 1994).

Although there is a significant body of evidence linking NS and reading ability, the studies report inconsistent results. These inconsistencies can be attributed to many factors, which may be attributed to three factors:

1) The nature of the naming task (discrete or sequential) and the type of stimuli (letters, digits, colors and 
simple objects). This factor is important because different types of stimuli require different cognitive abilities, and understanding the role the task's format plays in the relationship to reading strengths, and the relationship between NS and reading in general. Different studies investigated different types of naming tasks, leading to different results and confusion in the literature.

2) Which aspect of reading is being investigated, accuracy or fluency. The definition of reading has undergone major changes. While dyslexics were once identified only by measures of accuracy, today the definition includes fluency. The nature of the reading task (i.e., single word or connected text) has also contributed to the inconsistencies of the relationship.

3) The effect of the orthographic depth of the language in which the study was carried out. The orthographic depth term is related the relationship between the orthographic and the phonologic systems regardless of word frequency. Shallow orthographies have a one-to-one relationship between its graphemes and phonemes, and the spelling of words is very consistent (e.g. Italian, spanish and Finnish). Deep orthographies on the other hand, are writing systems that do not have a one-to-one correspondence between sounds (phonemes) and the letters (graphemes) that represent them (e.g. English, French or morphophonemic as Korean) (Frost, 2005).

The classic test is the RAN task created by Denckla and Rudel (1974), in which participants are required to name an array of familiar digits, pictures, letters, or color patches in sequential order, as rapidly as possible. Each set consists of 5 letters (or digits, or colors, or objects) that frequently appear in the language, and these stimuli are repeated 10 times in 5 rows, for a total of 50 stimuli. The final score is the overall time required to name all the stimuli in the set. A significant connection between NS and reading ability has been found for the RAN tasks, and a weaker connection for discrete naming tasks (Breznitz, 2006).

Perfetti, Finger, and Hogaboam (1978) found no difference in NS between good and bad readers when naming was examined using a discrete naming test. Bowers and Swanson (1991) found that discrete NS and sequential NS are significantly related to length of word recognition and to comprehension among children in second grade. However, only sequential NS was significantly related to accuracy of word and pseudoword recognition among these children. Swanson (1989) claimed that the cognitive requirements of sequential naming are more similar to those of the reading process. Both processes require lexical access and retrieval within the context of scanning and tracking material which is presented sequentially. According to Swanson, discrete naming tasks remove the important source of variance that naming shares with reading.

At the present stage of theory development, the main issue is whether rate-related linguistic functions like NS are related to a domain-general timing mechanism, to more specific perceptual linguistic or motoric sources, or to a combination of factors (see, Farmer \& Klein 1995; Tallal et al., 1996). While this is an important issue, the aim of this study is to determine the contributions of the NS to reading ability. This requires a look at the less researched relationship between NS and reading fluency.

\section{Reading Fluency}

Dyslexic subjects have usually been identified solely on the basis of word reading accuracy measures, which excludes children who are accurate but slow from scientific investigations and clinical interventions (Wolf et al., 2002). However, in recent years, the issue of fluency has evoked interest among researchers dealing with reading and dyslexia, resulting in the inclusion of the term fluency in the current definitions of the dyslexia phenomenon as a separate factor from accuracy (Lyon et al., 2003). Nevertheless, there is still no consensus on the definition of fluency as related to reading. Nor is there agreement about whether fluency is a dependent variable and as such represents a diagnostic measure for the quality of reading, or whether it is an independent variable that affects the quality of reading.

Several hypotheses have been suggested to explain decreased reading rate based on the assumption that word reading rate is a dependent variable. Greene et al. (1994) proposed that the level of word reading accuracy, the reader's age, acquaintance with reading skills, and development of word reading automaticity all account for decreased reading rate. Perfetti (1977) claimed that slow word recognition interferes with reader's ability to retain large units of text in the working memory (bottleneck theory), which prevents reading from being efficient. The basic view among researchers positing reading rate as a dependent factor is based on the claim that reading is a linguistic process.

Share and Leikin (2004) stressed the importance of distinguishing between lexical versus supra-lexical levels of reading. According to their view, "the existing literature on language and reading has adopted a variety of reading tasks as nearly interchangeable measures of an undifferentiated reading entity. This holistic or uni-dimensional approach has been superseded by an extensive research literature pointing to an important distinction 
between processes operating at the level of the identification of individual words, as opposed to processes operating beyond the individual word concerned with the integration of information across groups of words, phrases, sentences, and texts” (p. 89).

Alphabetical written language systems vary widely in consistency of correspondence between graphemes and phonemes. In a continuum of the predictability of graphemes-phoneme relationships, at one extreme are languages with a high degree of orthographic transparency, such as Spanish, in which the mapping between graphemes and phonemes is largely consistent, and languages with an opaque orthography, such as English, in which there are many ways of sounding out graphemes, and many of the correspondences cannot be predicted from context-dependent grapheme-phoneme rules.

Smythe, Everatt and Salter (2004) examined the literacy difficulties experienced by children learning to read and write Chinese, English, and Hungarian and found that good and poor literacy learners were differentiated by different cognitive factors across the three languages. Further evidence of the importance of orthography transparency comes from studies in which word recognition and nonword decoding processes develop faster in more transparent orthographies (Everatt \& Zabell, 2002). This relationship between the rate of literacy improvements and orthographic transparency suggests that there may be fewer problems with learning a more transparent orthography than a less transparent one, which might mean that dyslexia as a word-level literacy learning difficulty may be less evident in languages that use a relatively simple relationship between letters and sounds (Zeigler \& Goswami, 2005; Smythe et al., 2004). This claim was supported in other studies. Seymour, Aro, and Erskine (2003) compared the abilities of first grade children to read familiar words and simple nonwords in English and 12 other European orthographies. Children from most European countries were accurate and fluent in reading before the end of the first school year, with word reading accuracies exceeding $90 \%$ in all except the more opaque orthographies of Portuguese, French, Danish, and particularly English. In Arabic, which is considered a shallow orthography, a different picture emerged. Azzam (1993) examined the errors in reading and writing made by children learning Arabic in a developmental framework and found that errors in reading and spelling persisted throughout elementary school, pointing to the difficulties involved in mastering the Arabic written language. She claimed that children reading in Arabic perform more mistakes than children reading in English.

Share (2008) recently argued that "the extreme ambiguity of English spelling-sound correspondence has confined reading science to an insular, anglocentric research agenda addressing theoretical and applied issues with limited relevance for a universal science of reading” (p. 584). Wolf and Bowers (1999) suggested that cross-linguistic data support their claim that the particular role forced on phonological-based processes has obscured the critical, differential role played by processes underlying NS performance. Other authors (Jimenez et al., 2008; Wimmer et al., 2000; Wolf \& Bowers, 1999) claimed that within the family of alphabetic languages, the types of cognitive difficulties faced by individuals with dyslexia when learning to read in their native languages might be different because of the relationship of the spoken and written forms of the language, and that in more regular languages with lower phonological demands, NS deficits should appear as a stronger characteristic of readers with disability.

This shift of focus to the importance of NS and its relation to orthographic transparency followed repeated reports of different patterns of reading dyslexia in different languages. Seymour et al. (2003) attributed these findings to the orthographic depth of the language, which affected both word and non-word decoding. According to these findings, the rate of learning to read in English was more than two times slower than in the other orthographies. Research in Spanish language showed that the presence of deficit in RAN affected measures of fluency. Wimmer et al. (2000) found similar results in a study in German in which an early NS deficit was predictive of later reading fluency impairments, and was consistent with the opposite findings that German dyslexic children (defined by poor reading fluency) exhibit a massive concurrent NS deficit but little phonological awareness deficit.

In Arabic, the picture is somewhat complicated. On the one hand, Arabic is considered a shallow orthography (as will be later elaborated), on the other hand, Arabic is a typical case of diglossia, meaning, it includes two different versions.

\section{The Nature of Arabic}

The classical definition of diglossia, proposed by Ferguson (1959), is that it is a stable linguistic state that includes different spoken dialects and a totally different literary language, which is usually grammatically complicated, as distinct from the different spoken dialects, and includes a respectable written literature. This literary version is studied in school and is not acquired naturally without formal learning. It is the language for formal 
communication and is not the language of day-to-day conversation. A diglossic context has two features: a differentiation between the written and the oral modes; and rigid socio-functional complementarities of two separate sets of functions performed by two markedly distinct, though linguistically related, codes.

Arabic is a typical case of diglossia. According to Saiegh-Haddad (2005), modern standard Arabic (MSA) is the language used throughout the Arabic speaking world for writing and some other formal functions, such as speeches and religious sermons, while the spoken Arabic vernacular (SAV) is the language used for everyday conversation. Though SAVs are all linguistically related to MSA, they are distinct and structurally markedly distant from it. The linguistic distance between MSA and SAV spans the phonological, morpho-syntactic, and lexical-semantic domains (Saiegh-Haddad, 2005). Ayari (1996) and Abu-Rabia (2000) agree with the above definition of diglossia and the linguistic distance described by Saiegh-Haddad (2005). Ayari (1996) adds that this diglossic situation of the Arab world hinders children's acquisition of reading in Arabic. They encounter difficulties already in first grade when they are required to study literary Arabic, which is a totally different language from spoken Arabic. In addition, he notes, unfortunately preschool children are not exposed to literary Arabic because there is near consensus in the Arab world that literary Arabic is difficult for them and they should not be exposed to it before first grade. Parents, teachers and educators share this belief. Consequently, these children encounter literary Arabic in first grade almost as a second language. According to Ayari (1996), this means that children are required to cope simultaneously with reading and writing in a second language (literary Arabic). He argues for early exposure of these children to literary Arabic, in the preschool period, as the proper strategy to enhance their Arabic-reading acquisition.

Ibrahim (2009) reports findings that provide cognitive basis of diglossia in Arabic. In his study, repetition priming effects were compared within spoken Arabic (SA), as well as with the effects found when primes were in either literary Arabic (LA) or Hebrew. The results show that lexical decisions for words in SA were not influenced by previous presentations of translation equivalents in LA. Findings from an earlier study by this author on semantic priming effects (Ibrahim et al., 2002) suggest that the status of LA is similar to that of Hebrew and is consistent with the typical organization of second language (L2) in a separate lexicon. Thus, learning LA appears to be, in some respects, more like learning a second language than like learning the formal register of one's native language (p. 93).

In addition to its diglossic nature, two other features play essential roles in assessing reading and examining the predicative power of different processes of the Arabic language: morphology and orthography.

Most research was conducted with the English language, which, unlike the transparent orthography of Arabic, was classified as a deep orthography language. The present study aims to fill this vacuum. Therefore, the following questions were addressed:

1) What is the relationship between NS variables and the two types of reading measures: pseudoword and single word reading in each grade level?

2) What is the relative contribution of NS to accuracy at the two levels of reading in each grade level?

Based on the literature from the English language about the nature of the relationship among the variables investigated, and in view of the unique graphemic complexity and the diglossic nature of the Arabic language it is hypothesized that NS measures will correlate with fluency measures.

\section{Method}

\section{Participants}

117 native Arabic speaking children were randomly selected from two public schools in a city in northern Israel: 58 pupils were in third grade (mean age: 8.4 years, SD 4.15 months) and 59 were in fifth grade (mean age: 12.36 years, SD 3.51 months). All of the children came from a middle socio-economic background, were born and resided in the same city, and spoke the same local vernacular.

\section{Measures}

\section{Independent Measures}

\section{Rapid automatized naming $\{R A N\}$}

The test is comprised of two subtests: one for letters and one test for numbers. The test was modeled after Denckla and Rudell (1974). Children were asked to name five letters ( The letters and the digits were arranged randomly in five rows of ten letters/digits each. A practice session in which the children were asked to name the five letters and digits preceded the timed trial. All the children accurately named all five digits and all five letters. In the actual trial, the children were required to name the letters 
and digits as quickly as they could. The time it took a child to name all digits and letters was recorded as the أ، س، : ج

\section{Dependent Measures}

Pseudoword Reading

Difficulty reading aloud pseudowords has been shown to be one of the most discriminating measures of individual differences in reading ability (Rack, Snowling, \& Olsen, 1992; Share, 1995; Stanovich \& Seigel, 1994). A test of pseudoword reading was developed for the study consisting of 24 pseudowords of 2 - 4 syllables each. The pseudowords were created by manipulating the letters of words chosen from the single word test; these words were all pointed.

\section{Single Word Reading}

A test of single word reading was developed for the study. The pool of words was chosen from third, fourth and fifth grade textbooks. To reach independent tests of stimuli, six language teachers from three Arab schools in northern Israel were asked to evaluate lists of words for the grade appropriateness of frequency, number of letters, number of syllables, orthographic density and morpho-phonemic structure.

Procedure

Children were tested individually in a quiet room at school and each child was administered all the tasks on the same day.

Every child was asked to read two lists: words and pseudowords. Following a short practice trial with 4 words and 4 pseudowords, the children were asked to pronounce the lists as fast as possible. The score was the number of words or pseudowords read accurately and the time it took the participant to read these words.

The responses were both tape-recorded and noted on scoring sheets that were cross-validated against the tape recorded responses.

\section{Results}

Descriptive statistics for the measures administered to third and fifth graders are presented in Table 1. All accuracy scores are presented as raw scores. Interestingly, there is hardly any difference between the total accuracy and the time in seconds of the pseudowords in third grade and fifth grade.

The relationship between NS and reading variables (pseudo-word, single word and text reading) were measured (see Table 2). The findings for third grade indicate that LNS scores were significantly correlated with all accuracy and fluency reading variables. The strongest correlations were evident in the fluency measures: pseudo time in seconds $(r=.44, p<.01)$ and single word time in seconds $(r=.53, p<.01)$. Weaker, but significant correlations were found between LNS and accuracy measures at the two levels of reading $(r=.26, p<.05)$, single word $(r=.30, p<.05)$. The NNS measure, was also significantly correlated with fluency measures: pseudoword $(r=.45, p<.01)$ and single word $(r=.54, p<.01)$.

In fifth grade, LNS was significantly correlated with pseudo-word accuracy and fluency measures $(r=-.33, p$ $<.01, r=.44, p<.01$ ), while there is significant correlation with fluency measures, there is no significant correlation with accuracy measures. The NNS was significantly correlated with all accuracy and fluency measures except with the accuracy measure at single word level.

Table 1. Descriptive statistics for all research variables according to grades.

\begin{tabular}{|c|c|c|c|c|c|c|}
\hline \multirow[b]{2}{*}{ Variables } & \multicolumn{3}{|c|}{ Grade $3(\mathrm{~N}=58)$} & \multicolumn{3}{|c|}{ Grade $5(\mathrm{~N}=59)$} \\
\hline & Range & Mean & $\mathrm{SD}$ & Range & Mean & $\mathrm{SD}$ \\
\hline \multicolumn{7}{|l|}{ NS } \\
\hline LNS time in seconds (50 letters) & 84.80 & 51.98 & 17.26 & 52.06 & 43.40 & 11.25 \\
\hline NNS time in seconds (50 numbers) & 57.81 & 33.94 & 9.87 & 24.98 & 26.64 & 4.56 \\
\hline Total number of correct pseudo words (24 item) & 21.00 & 11.24 & 5.63 & 21.00 & 11.56 & 5.63 \\
\hline Pseudo time in seconds & 162.73 & 88.12 & 31.49 & 158.16 & 81.03 & 35.07 \\
\hline Total number of correct words (74 word) & 60.00 & 43.02 & 16.41 & 67.00 & 51.81 & 15.35 \\
\hline Single words time in seconds & 349.68 & 194.66 & 78.55 & 268.60 & 142.40 & 54.65 \\
\hline
\end{tabular}


Table 2. Pearson correlations among letter naming, phonological awareness and reading variables in each grade level.

\begin{tabular}{ccccc}
\hline & \multicolumn{2}{c}{ Grade 3 $(\mathrm{N}=58)$} & \multicolumn{2}{c}{ Grade $5(\mathrm{~N}=59)$} \\
\cline { 2 - 4 } & LNS & NNS & LNS & NNS \\
\hline Pseudo-words & & & & $-.30^{*}$ \\
Accuracy & $-.27^{*}$ & -.17 & $-.33^{* *}$ & $.34^{* *}$ \\
Fluency & $.44^{* *}$ & $.45^{* *}$ & $.44^{* *}$ & -.17 \\
Single Words & & & -.25 & $.42^{* *}$ \\
Accuracy & $-.30^{*}$ & -.11 & $.39^{* *}$ & $.54^{* *}$ \\
Fluency & $.53^{* *}$ & & & \\
\hline
\end{tabular}

${ }^{*} p<.05 ;{ }^{* *} p<.01$.

\section{Discussion}

Naming speed (NS) is an ability found to have a strong relationship with reading in many languages (e.g., Wolf, O'rouke, Gidney, Lovett, Cirino, \& Morris, 2002). It was assumed that like phonological awareness. NS is a key component in the development of reading measures especially those related to fluency. However, it is clear that the roles of different aspects of reading vary in their importance and contribution to reading development based on the characteristics of specific languages.

The main goal of this study was to investigate the relationship between NS measures and reading pseudowords and single words in Arabic language in third and fifth grade. Two measures were used to assess NS ability: letter naming speed (LNS) and number naming speed (NNS). In regard to the relationship between naming speed and reading pseudowords and single words, the hypothesis predicted that NS variables will correlate with fluency measures were supported partially. It was also hypothesized that both NS measures (LNS and NNS) will be correlated in both third and fifth grade. The results showed both NS measures were significantly correlated with fluency. These results indicate that naming speed ability is crucial for the fluency aspect of reading. However, there was no apparent difference in the magnitude of correlations at the two levels of reading (pseudowords and words).

Unexpected correlations were witnessed between some measures of NS and reading. For example, in third grade, LNS significantly correlates, although modestly, with accuracy. In fifth grade, NS correlates with accuracy in reading pseudowords, but not with single words. Similar results were found in other transparent orthographies (Katzir et al., 2006). This greater role played by NS measures in reading (the connection between NS measures and accuracy) was witnessed in other transparent orthographies such as German (Wimmer et al., 2000), Spanish (Escribano \& Katzir, 2008), Chinese and Hungarian (Smythe, Everatt, \& Salter, 2004).

Dissociation between LNS and NNS was also witnessed in the third grade. While both measures correlate with fluency, only LNS correlated with accuracy. Most research didn't differentiate between letter naming speed and number naming speed but rather treated them as a one unitary alphanumeric ability. Van den Bos, Zijlstra, and Spelberg (2002) addressed this issue and examined closely the interrelations between continuous-naming tasks. They noted that conclusions in various previous studies were based on rather superficial evidence. That is, the relative closeness of mean NS of numbers and letters on the one hand and the relative closeness of color-and picture-naming speeds on the other hand were considered sufficient basis for distinguishing alphanumeric and nonalphanumeric composite scores (Meyer, Wood, Hart, \& Felton, 1998). In their study they found an unstable pattern at the levels of 8- and 10-year-olds, whereas easily interpretable and stable two-factor pattern emerged at the age levels of 12, 16 and mature adulthood. Thus, developmentally, an increased common speed factor can be observed as well as differentiated and increasingly independent pattern of alphanumeric associations. They interpreted the later finding as reflecting a gradual strengthening of initially loosely connected alphabetic and numeric access routes into an integrated alphanumeric lexical network. They further argue that this development can be explained by the hypothesis that letter- and number-naming speed interact with both reading and arithmetic practice.

\section{Conclusion}

The main goal of the present study was to explore the relationship between naming speed abilities and reading 
pseudowords and single words in Arabic language in third and fifth grade.

Taking into consideration the main features of the Arabic language, this study showed a significant relationship between naming speed measures and reading fluency. Furthermore, the whole findings illustrated the importance of using different NS measures as assessment tools in reading in Arabic. Based on the results of the present study it seems more accurateness to conceptualize naming speed skills as assessing separate abilities have different relation to reading.

\section{References}

Abu-Rabia, S. (2000). Effects of Exposure to Literary Arabic on Reading Comprehension in a Diglossic Situation. Reading and Writing: An Interdisciplinary Journal, 13, 147-157. http://dx.doi.org/10.1023/A:1008133701024

Ayari, S. (1996). Diglossia and Illiteracy in the Arab World. Language and Culture and Curriculum, 9, $243-252$. http://dx.doi.org/10.1080/07908319609525233

Azzam, R. (1993). The Nature of Arabic Reading and Spelling Errors of Young Children. Reading and Writing, 5, 355-385. http://dx.doi.org/10.1007/BF01043112

Badian, N. A. (1997). Dyslexia and the Double Deficit Hypothesis. Annals of Dyslexia, 47, 69-88. http://dx.doi.org/10.1007/s11881-997-0021-y

Bowers, P. G., \& Swanson, L. B. (1991). Naming Speed Deficits in Reading Disability: Multiple Measures if a Singular Process. Journal of Experimental Child Psychology, 51, 195-219. http://dx.doi.org/10.1016/0022-0965(91)90032-N

Bowers, P. G., \& Wolf, M. (1993). Theoretical Links among Naming Speed, Precise Timing Mechanisms, and Orthographic Skill in Dyslexia. Reading and Writing: An Interdisciplinary Journal, 5, 69-85. http://dx.doi.org/10.1007/BF01026919

Breznitz, Z. (2006). Fluency in Reading: Synchronization of Processes. New Jersey, NJ: Lawrence Erlbaum Associates.

Denckla, M. B., \& Rudel, R. G. (1974). Rapid Automatized Naming of Pictured Objects, Colors, Letters and Numbers by Normal Children. Cortex, 10, 186-202. http://dx.doi.org/10.1016/S0010-9452(74)80009-2

Denckla, M. B., \& Rudel, R. G. (1976a). Naming of Objects by Dyslexic and Other Learning Disabled Children. Brain and language, 3, 1-15. http://dx.doi.org/10.1016/0093-934X(76)90001-8

Denckla, M. B., \& Rudel, R. G. (1976b). Rapid Automatized Naming (R.A.N): Dyslexia Differentiated from Other Learning Disabilities. Neuropsychologia, 14, 471-479. http://dx.doi.org/10.1016/0028-3932(76)90075-0

Escribano, C. L., \& Katzir, T. (2008). Are Phonological Processes Separate from Naming Speed in a Shallow Orthography? Education and Psychology, 6, 641-666.

Everatt, J., \& Zabell, C. (2002). Surface and Phonological Subtypes of Adult Dyslexia. Dyslexia, 8, 160-177. http://dx.doi.org/10.1002/dys.223

Farmer, M. E., \& Klein, R. M. (1995). The Evidence for Temporal Processing Deficit Linked to Dyslexia: A Review. Psychonomic Society, 2, 460-493. http://dx.doi.org/10.3758/BF03210983

Ferguson, C. A. (1959). Diglossia. Word, 14, 47-56.

Frost, R. (2005). Orthographic Systems and Skilled Word Recognition Processes in Reading. In M. J. Snowling, \& C. Hulme (Eds.), The Science of Reading: A Handbook (pp. 272-295). Oxford: Blackwell.

http://dx.doi.org/10.1002/9780470757642.ch15

Geshwind, N. (1972). Language and the Brain. Scientific American, 226, 76-83. http://dx.doi.org/10.1038/scientificamerican0472-76

Greene, B. A., \& Royer, J. M. (1994). A Developmental Review of Response Time Data That Support a Cognitive Components Model of Reading. Educational Psychology Review, 6, 141-172. http://dx.doi.org/10.1007/BF02208971

Ibrahim, R. (2009). The Cognitive Basis of Diglossia in Arabic: Evidence from Repetition Priming Study within and between Languages. Psychology Research and Behavior Management, 12, 95-105.

Jimenez, E. J., Hernandez, V. I., Rodriguez, C., Guzman, R., Diaz, A., \& Ortiz, R. (2008). The Double-Deficit Hypothesis in Spanish Developmental Dyslexia. Top Lang Disorders, 28, 46-60. http://dx.doi.org/10.1097/01.adt.0000311415.69966.76

Katzir, T., Wolf, M., O’Brien, B., Kennedy, B., Lovett, M., \& Morris, R. (2006). Reading Fluency: The Whole Is More than the Parts. Annals of Dyslexia, 56, 51-82. http://dx.doi.org/10.1007/s11881-006-0003-5

Lyon, G. R., Shaywitz, S. E., \& Shaywitz, B. A. (2003). Defining Dyslexia, Comorbidity, Teacher’s Knowledge of Language and Reading: A Definition of Dyslexia. Annals of Dyslexia, 53, 1-14. http://dx.doi.org/10.1007/s11881-003-0001-9

Meyer, M. S., \& Felton, R. H. (1999). Repeated Reading to Enhance Fluency: Old Approaches and New Direction. Annuals of Dyslexia, 49, 283-306. http://dx.doi.org/10.1007/s11881-999-0027-8

Meyer, M. S., Wood, F. B., Hart, L. A., \& Felton, R. H. (1998). Longitudinal Course of Rapid Naming in Disabled and Non- 
disabled Readers. Annuals of Dyslexia, 48, 91-114.

http://dx.doi.org/10.1007/s11881-998-0005-6

Perfetti, C. A. (1977). Language Comprehension and Fast Decoding: Some Psycholinguistic Prerequisites for Skilled Reading Comprehension. In J. T. Guthrie (Ed.), Cognition, Curriculum and Comprehension (pp. 20-41). Newark, DE: International Reading Association.

Perfetti, C. A., Finger, E., \& Hogaboam, T. W. (1978). Sources of Vocalization Latency Differences between Skilled and Less Skilled Young Readers. Journal of Educational Psychology, 70, 730-739. http://dx.doi.org/10.1037/0022-0663.70.5.730

Saiegh-Haddad, E. (2005). Correlates of Reading Fluency in Arabic: Diglossic and Orthographic Factors. Reading and Writing: An Interdisciplinary Journal, 18, 559-582. http://dx.doi.org/10.1007/s11145-005-3180-4

Scarborough, H. S. (1998a). Early Identification of Children at Risk for Reading Disabilities: Phonological Awareness and Some Other Promising Predictors. In B. K. Shapiro, P. J. Accardo, \& A. J. Capute (Eds.), Specific Reading Disability: A View of the Spectrum (pp. 75-119). Timonium, MD: York Press.

Seymour, P. H. K., Aro, M., \& Erskine, J. M. (2003). Foundation Literacy Acquisition in European Orthographies. British Journal of Psychology, 94, 143-174. http://dx.doi.org/10.1348/000712603321661859

Share, D. L. (2008). On the Anglocentricities of Current Reading Research Practice: The Perils of Over-Reliance on an “Outlier” Orthography. Psychological Bulletin, 134, 584-615. http://dx.doi.org/10.1037/0033-2909.134.4.584

Share, D. L., \& Leiken, M. (2004). Language Impairment at School Entry and Later Reading Disability: Connections at Lexical versus Supralexical Levels of Reading. Scientific studies of Reading, 8, 87-110.

http://dx.doi.org/10.1207/s1532799xssr0801_5

Smythe, I., Everatt, J., \& Salter, R. (Eds.) (2004). The International Book of Dyslexia. London: Wiley.

Swanson, L. B. (1989). Analyzing Naming Speed-Reading Relationships in Children. Unpublished Doctoral Dissertation, Water- loo, Ontario: University of Waterloo.

Tallal, P., Miller, S. L., Bedi, G., Byma, G., Wang, X., Nagarajan, S., Schreiner, C., Jenkins, W., \& Merzenich, M. (1996). Language Comprehension in Language-Learning Impaired Children Improved with Acoustically Modified Speech. Science, 271, 81-84. http://dx.doi.org/10.1126/science.271.5245.81

Van den Bos, K. P. (1998). IQ, Phonological Awareness and Continuous-Naming Speed Related to Dutch Poor Decoding Children's Performance on Two Word Identification Tests. Dyslexia, 4, 73-89. http://dx.doi.org/10.1002/(SICI)1099-0909(199806)4:2<73::AID-DYS104>3.0.CO;2-\#

Van den Bos, K. P., Zijlstra, B. J. H., \& Spelberg, H. C. (2002). Life Span Data on Continuous Naming Speeds of Numbers, Letters, Colors, and Pictured Objects, and Word Reading Speed. Scientific Studies of Reading, 6, 25-49. http://dx.doi.org/10.1207/S1532799XSSR0601_02

Wagner, R. K., \& Torgensen, J. K. (1987). The Nature of Phonological Processing and Its Causal Role in the Acquisition of Reading Skills. Psychological Bulletin, 101, 192-212. http://dx.doi.org/10.1037/0033-2909.101.2.192

Wagner, R. K., Laughon, P. L., Simmons, K., \& Rashotte, C. A. (1993). Development of Young Readers’ Phonological Processing Abilities. Journal of Educational Psychology, 85, 83-103. http://dx.doi.org/10.1037/0022-0663.85.1.83

Wimmer, H. (1993). Characteristics of Developmental Dyslexia in a Regular Writing System. Applied Psycholinguistics, 14, 1-34. http://dx.doi.org/10.1017/S0142716400010122

Wimmer, H., Mayringer, H., \& Landerl, K. (2000). The Double-Deficit Hypothesis and Difficulties in Learning to Read a Regular Orthography. Journal of Educational Psychology, 92, 668-680. http://dx.doi.org/10.1037/0022-0663.92.4.668

Wolf, M., \& Bowers, P. (1999). The Question of Naming-Speed Deficits in Developmental Reading Disabilities: An Introduction to the Double-Deficit Hypothesis. Journal of Educational Psychology, 19, 1-24.

Wolf, M., O’Rourke, A. G., Gidney, C., Lovett, M., Cirino, P., \& Morris, R. (2002). The Second Deficit: An Investigation of the Independence of Phonological and Naming-Speed Deficits in Developmental Dyslexia. Reading and Writing: An Interdisciplinary Journal, 15, 43-72. http://dx.doi.org/10.1023/A:1013816320290

Yap, L. R., \& Van der Leij. (1994). Word Processing Dyslexics. An Automatic Decoding Deficit? Reading and Writing, 5, 261-279. http://dx.doi.org/10.1007/BF01027391

Zeigler, J. C., \& Goswami, U. (2005). Reading Acquisition, Developmental Dyslexia, and Skilled Reading across Languages: A Psycholinguistic Grain Size Theory. Psychological Bulletin, 131, 3-29. http://dx.doi.org/10.1037/0033-2909.131.1.3 
Scientific Research Publishing (SCIRP) is one of the largest Open Access journal publishers. It is currently publishing more than 200 open access, online, peer-reviewed journals covering a wide range of academic disciplines. SCIRP serves the worldwide academic communities and contributes to the progress and application of science with its publication.

Other selected journals from SCIRP are listed as below. Submit your manuscript to us via either submit@scirp.org or Online Submission Portal.
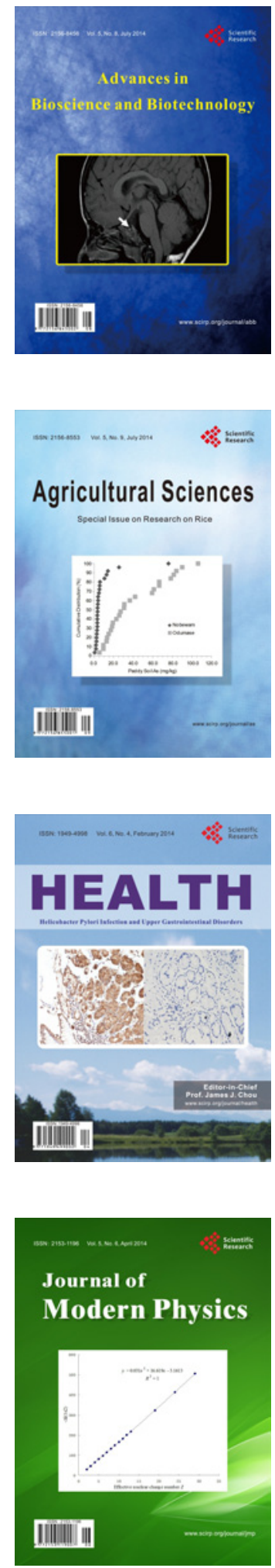
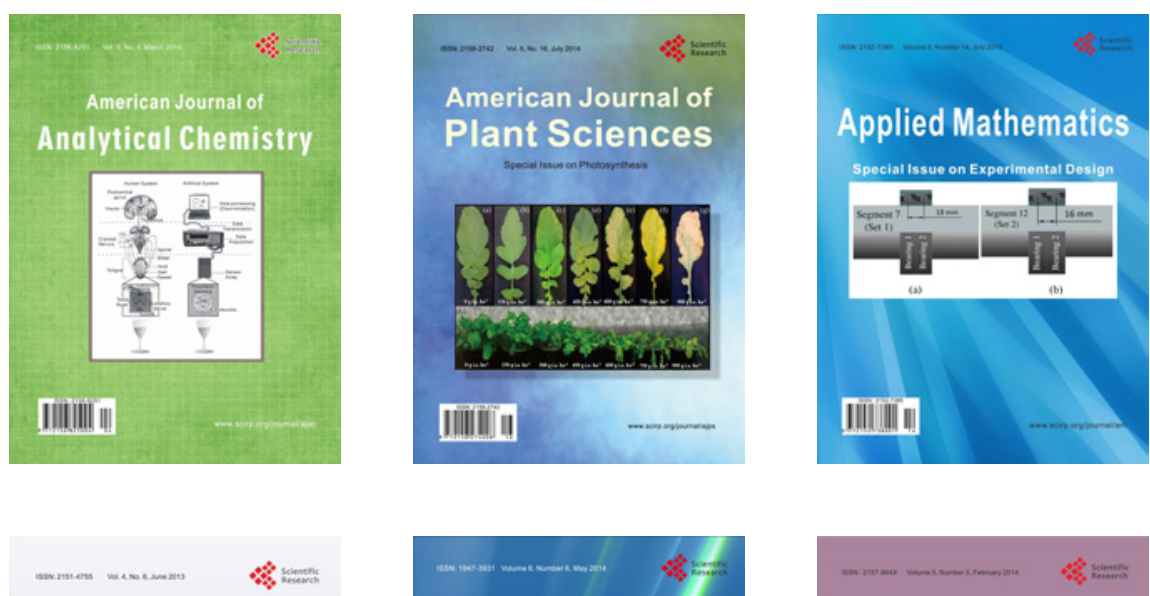

Creative Education
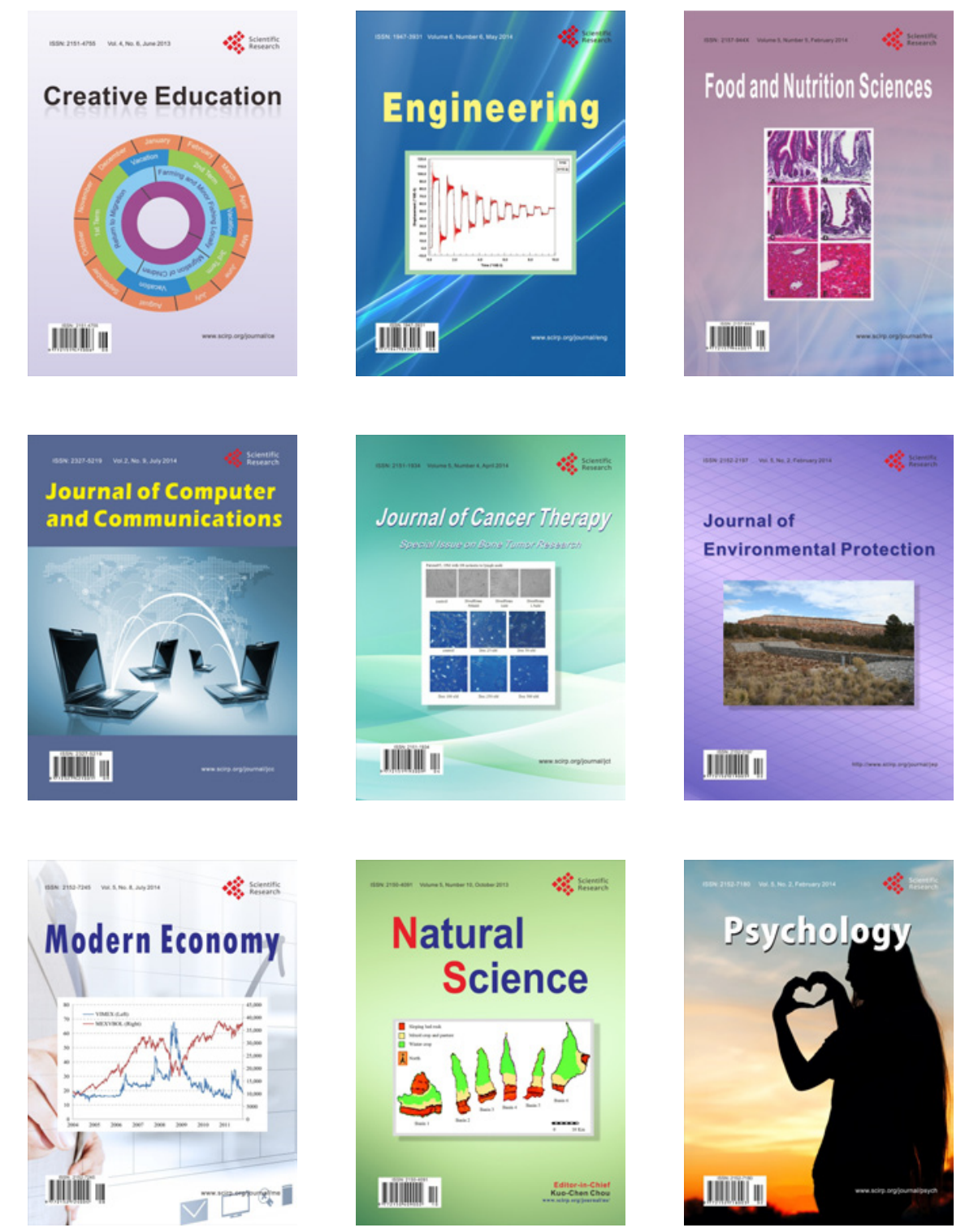